\title{
Managed Care Pharmacy Residencies, Fellowships, and 0ther Programs
}

$\mathrm{T}$ he following is a partial list of available managed care pharmacy residency and fellowship programs and other programs compiled as of August 2005. The residencies listed were submitted by AMCP members in response to AMCP's call for residency program listings. This is not a comprehensive list of all available programs. AMCP provides it solely as a service

\section{AMERICA SERVICE GROUP}

\section{Managed Care}

Accredited: Yes

Length of Program: 1-year, 2-year option

Number of Positions: 1

Affiliation: Various universities

Application Deadline: February 15

Starting Date: July 1

Estimated Stipend: $\quad \$ 35,000$

Onsite Interview: Yes

Educational/Special Requirements: Graduate of accredited school of pharmacy

Fringe Benefits: 3 weeks paid personal leave, paid sick leave, full medical and dental, tuition assistance toward specified degree programs

Special Features: America Service Group is a closed-model HMO that provides comprehensive at-risk health care; Secure Pharmacy Plus is the pharmacy benefits manager.

Contact Information:

Peter Mikhail

Vice President, Clinical Services

American Service Group/Secure Pharmacy Plus

416 Mary Lindsay Polk Dr., Suite 515

Franklin, TN 37067

(615) 771-1457

(615) 771-4557 (fax)

peter.mikhail@securepp.com

\section{AMERICAN HEALTH CARE}

\section{Clinical Therapeutics / Managed Care Pharmacy}

Accredited:

Being pursued

Length of Program: 12 months

Number of Positions: 1

Affiliation: None

Application Deadline: Open

Starting Date: July 1

Estimated Stipend: $\quad \$ 43,000$ and up

Onsite Interview: Yes

Educational/Special Requirements: PharmD with a California to its readers. This list does not imply AMCP's endorsement of any particular program nor does AMCP guarantee the availability of any of the programs listed. AMCP does not assume responsibility for any errors that may appear in these listings. If you are aware of additional residency and fellowship programs not listed here, please contact AMCP at (800) TAP-AMCP.

pharmacist license or eligibility for licensure

Fringe Benefits: Medical, dental, vision, holidays, vacation, and attendance at national conference(s)

Special Features: Activities the resident will be involved in include, but are not limited to, P\&T committee participation and presentations; formulary management and review; one-onone physician correspondence on evidence-based medicine with current clinical studies reviewed and presented, focusing on actual patients who may benefit from this information; new drug review and its placement with available therapies; clinical participation and set-up; client summary report write-up and delivery; participation in various education conference and clinical studies.

Contact Information:

Nazly Westernoff

American Health Care

3001 Douglas Blvd., \#320

Roseville, CA 95661

(916) 773-7227

(916) 773-7210 (fax)

nazly@americanhealthcare.com

\section{AON CONSULTING}

Pharmacy Benefits Consulting

Accredited: No

Length of Program: 12 months

Number of Positions: 2

Affiliation: None

Application Deadline: January 3

Starting Date: July 5

Estimated Stipend: $\quad \$ 36,000$

Onsite Interview: Yes

Educational/Special Requirements: PharmD, managed care course work preferred

Fringe Benefits: 2 weeks paid vacation, paid holidays, medical/dental insurance, travel budget, professional meetings

Special Features: Aon Consulting is the second largest employee benefits consulting firm nationwide. This unique program provides residents with the opportunity to help 
employers and health plans better manage and control the prescription drug benefit for their employees or members. Residents will be exposed to all aspects of pharmacy benefit management consulting: plan design modeling, formulary analysis, clinical programming, disease management, audits, regulatory, trends and forecasting through proprietary actuarially based models. Residents will interact with benefit administrators, major PBMs, PPOs, HMOs, and disease management firms nationally. Currently, there are 2 resident positions available, based in Chicago, IL, and Philadelphia, PA.

\section{Contact Information:}

Connie Perry

Vice President

Aon Consulting

330 East Kilbourn Ave., Suite 450

Milwaukee, WI 53202

(414) 225-5345

(414) 276-3929 (fax)

connie_f_perry@aon.com

\section{APPLIED HEALTH OUTCOMES}

\section{Health Outcomes Research Fellowship}

Accredited: No

Length of Program: 2 years

Number of Positions: 1

Affiliation: $\quad$ University of South Florida, College of Public Health

Application Deadline: January 3

Starting Date: July 1

Estimated Stipend: Contact program

Onsite Interview: Yes

Educational/Special Requirements: PharmD or equivalent (residency preferred)

Fringe Benefits: Competitive salary, health insurance, vacation, 401(k), tuition for required classes, and travel expenses to 1 national meeting per year

Special Features: This 2-year, degree-granting fellowship provides a unique research and education experience in an outcomes consulting environment. Research activities include, but are not limited to, quality improvement programs, database analysis, economic modeling, and development of researchbased manuscripts. In addition, the fellow will obtain an MSPH or MPH degree from the University of South Florida, College of Public Health.

\section{Contact Information:}

James H. Jackson IV, PharmD, MPH

Senior Consultant

Applied Health Outcomes

4114 Woodlands Pkwy., Suite 500

Palm Harbor, FL 34685

(727) $771-4100$
(727) 771-4145 (fax)

jjackson@applied-outcomes.com

Web: http://www.applied-outcomes.com

\section{BIOSCRIP}

\section{Managed Care Pharmacy}

Accredited: No

Length of Program: 12 months

Number of Positions: 1

Affiliation: None

Application Deadline: February 1

Starting Date: July 1

Estimated Stipend: $\quad \$ 35,000$

Onsite Interview: Yes

Educational/Special Requirements: PharmD, licensure in the state of Ohio

Fringe Benefits: 10 vacation days, 5 holidays, 4 floating holidays, 2 personal days, health benefits, and professional travel allowance

Special Features: This 12-month residency program is designed to provide a firm knowledge base of managed care from the pharmacy benefit perspective and allows residents to excel in clinical services, formulary management and research, participation in formulary development and medication management, and provision of clinical services, including drug information, clinical program development, pharmacoeconomic assessment, and disease state management as well as the strengthening of written and verbal communication skills.

\section{Contact Information:}

Suzanne Tschida, PharmD, BCPS

Director, Clinical Services

BioScrip

10900 Red Circle Dr.

Minnetonka, MN 55343

(800) 444-5951, ext. 3621

(952) 352-6785 (fax)

stschida@bioscrip.com

\section{BLUE CROSS AND BLUE SHIELD OF ALABAMA}

\section{Managed Care}

Accredited:

AMCP/ASHP

Length of Program: 12 months

Number of Positions: 1

Affiliation: None

Application Deadline: January 15

Starting Date: July 1 (flexible)

Estimated Stipend: $\quad \$ 32,000$

Onsite Interview: Yes

Educational/Special Requirements: PharmD or equivalent experience 
Fringe Benefits: Paid vacation, personal holiday leave, health/dental insurance, no on-call responsibilities

Special Features: The program provides the resident with the opportunity to experience a true integrated medical and pharmacy system. The areas of focus will include pharmaceutical care, drug information, formulary management, clinical program management, disease state management, and outcome studies. The resident also will complete a research project suitable for publication. This program will incorporate communication and time management skills.

\section{Contact Information:}

Jerry Wong, PharmD, MBA

Residency Director

Blue Cross and Blue Shield of Alabama

450 Riverchase Pkwy., East

Birmingham, AL 35244

(205) 220-6526

(205) 220-2939 (fax)

jwong@bcbsal.org

BLUE CROSS AND BLUE SHIELD OF NEBRASKA

\section{Managed Care Pharmacy}

Accredited: Being pursued

Length of Program: 12 months

Number of Positions: 1

Affiliation:

University of Nebraska Medical Center

Application Deadline: January 16

Starting Date: July 1

Estimated Stipend: $\quad \$ 36,000$

Onsite Interview: Required

Educational/Special Requirements: PharmD degree from an ACPE-accredited college of pharmacy. Licensed pharmacist in the United States or eligibility for licensure (successful candidate must be fully licensed at the start of residency). Application requirements include: application, writing sample, 3 professional letters of recommendation, and onsite interview with short formal presentation.

Fringe Benefits: 10 days paid vacation, holidays, health insurance, paid travel and registration to AMCP Educational Conference and Annual Meeting

Special Features: The Blue Cross and Blue Shield of Nebraska residency will offer exposure to various aspects of managed care pharmacy through health plan and PBM exposure as well as direct patient care through clinical rotations. The residency will offer participation and exposure to the following areas: pharmacy benefit design, utilization management, formulary management, pharmacy trend management, drug information, health economic/outcomes research, pharmacy benefit management, disease state management quality assurance initiatives. This unique program also allows the resident the option to participate in teaching or didactic coursework through the
University of Nebraska Medical Center.

\section{Contact Information:}

Lee Handke

Vice President of Pharmacy and Wellness

Blue Cross and Blue Shield of Nebraska

7261 Mercy Rd.

Omaha, NE 68180

(402) 398-3884

(402) 548-4683 (fax)

lee.handke@bcbsne.com

\section{BLUE SHIELD OF CALIFORNIA}

Managed Care Pharmacy Systems

Accredited: AMCP/ASHP

Length of Program: 12 months

Number of Positions: 1

Affiliation: UCSF

Application Deadline: February 25

Starting Date: July 1

Estimated Stipend: $\quad \$ 46,000$

Onsite Interview: Yes

Educational/Special Requirements: PharmD degree from an accredited school of pharmacy, completion of a pharmacy practice residency or equivalent experience, 3 letters of recommendation, letter of intent, and onsite interview

Fringe Benefits: Health/dental/vision benefit; 20 days of paid time off, including professional leave (with travel allowances); and 9 holidays; no on-call responsibilities

Special Features: This residency instills the philosophy that health care outcomes need to be considered from all relevant perspectives (patient, provider, and payer). Residents participate in the development of drug policy, clinical guidelines, pharmacy benefits, and population-based disease management, pharmaceutical contracting support/analysis, and quality improvement. This program teaches residents to conceptualize, integrate, and transform accumulated experiences and knowledge into improved drug therapy for managed care patients.

Contact Information:

Tara Abrams

Senior Clinical Pharmacist, Quality Improvement

Blue Shield of California Pharmacy Services

50 Beale St., 22nd Fl.

San Francisco, CA 94105

(415) 229-6424

(415) 229-6011 (fax)

Tara.Abrams@blueshieldca.com 
CAREMARK, INC.

\section{Managed Care}

Accredited:

AMCP/ASHP

Length of Program:

12 months

Number of Positions: $\quad 3$ (1 each in Maryland, Texas, and Arizona)

Affiliation:

University of Maryland, University of

Arizona

Application Deadline: January 1

Starting Date: July 1

Estimated Stipend: $\$ 35,000$

Onsite Interview: Yes

Educational/Special Requirements: PharmD or equivalent

experience

Fringe Benefits: 2 weeks vacation, health insurance, free parking, professional meetings, and other management and pharmaceutical industry experience

Special Features: Off-site rotations, university affiliation at MD and AZ sites, ambulatory care clinic, disease management, industry experience

Contact Information:

Melissa Jay

Caremark, Inc.

750 West John Carpenter Fwy.

Irving, TX 75039

(469) $524-5832$

(469) 524-5858 (fax)

melissa.jay@caremark.com

CAREMARK, INC.

Managed Care Specialty-Analytics and Outcomes

Accredited: No

Length of Program: 12 months

Number of Positions: 2

Affiliation:

University of Illinois at Chicago; Midwestern University-Chicago College of Pharmacy

Application Deadline: January 3

Starting Date: July 1

Estimated Stipend: $\$ 38,000$

Onsite Interview: Yes

Educational/Special Requirements: PharmD with experiential or internship-based experience in managed care/PBM industry

Fringe Benefits: Comprehensive medical, dental, and life insurance plan; 2-week paid vacation; holidays; employee stock purchase program; flexible spending program; travel budget

Special Features: Caremark is a leading pharmaceutical services company, providing comprehensive drug benefit services to approximately 24 million participants throughout the United States. Caremark's clients include corporate health plans, managed care organizations, insurance companies, unions, government agencies, and other funded benefit plans. The
Analytics and Outcomes Residency will provide the resident a unique opportunity to work on initiatives that foster pro-active management of pharmaceutical and overall health care costs. It offers the ability to work with large data sets and perform various pharmaceutical cost analyses such as plan design modeling, formulary analysis, and clinical outcomes. As part of a core sales and account management team, the resident will have the opportunity to interact directly with clients, consultants, and various other benefit providers. While the focus is on analytics, the resident will be exposed to various areas in pharmacy benefit management such as clinical program development and implementation, operations, sales, account management, clinical sales support, marketing and communications, trade relations, pharmaceutical services, and therapeutic services.

Contact Information:

Anita Allemand

Director, Client Analytic Services, Inc.

Caremark, Inc.

2211 Sanders $R d$.

Northbrook, IL 60062

(847) 559-3923

(847) 559-5475 (fax)

anita.allemand@caremark.com

CLINICAL PHARMACOLOGY SERVICES, INC.

Ambulatory Care/Clinical Research

Accredited: No

Length of Program: 12 months

Number of Positions: 1

Affiliation: None

Application Deadline: February 1

Starting Date: June 1

Estimated Stipend: $\$ 34,000$

Onsite Interview: Yes

Educational/Special Requirements: None

Fringe Benefits: Sponsorship to professional meeting and

Southwestern Residency Conference

Special Features: None

Contact Information:

Daniel Buffington

Director

Clinical Pharmacology Services, Inc.

6285 E. Fowler Ave.

Tampa, FL 33617

(813) 983-1500

(813) 983-1501 (fax)

danbuffington@cpshealth.com

Web: http://www.cpshealth.com 
COVENTRY HEALTH CARE OF KANSAS, INC.

\section{Pharmacy Benefits Management}

Accredited: No

Length of Program: 12 months

Number of Positions: 1

Affiliation: University of Missouri-Kansas City (UMKC)

Application Deadline: January 6

Starting Date: July 1

Estimated Stipend: $\$ 32,000$

Onsite Interview: Yes

Educational/Special Requirements: PharmD degree from an ACPE-accredited college of pharmacy, licensed pharmacist in the United States or eligibility for licensure (successful candidate must be fully licensed at the start of residency), application, letter of intent, curriculum vitae, writing sample, official transcripts, 3 professional letters of recommendation, onsite interview with short formal presentation in Kansas City

Fringe Benefits: 2 weeks paid vacation; holidays; health insurance; paid travel and registration to AMCP Educational Conference, AMCP Annual Meeting, and ASHP Midyear Meeting

Special Features: Residency opportunities in all managed care core competencies: pharmacy benefit management, utilization management, formulary management, clinical consultation service, drug information, new technologies assessment, provider network relations, Medicare plan interventions, disease state management, health and wellness initiatives, quality assurance/improvement activities, marketing and sales, contracting, health economics/outcomes, rotations with pharmaceutical industry

Contact Information:

Shawn Burke

Director of Pharmaceutical Services

Coventry Health Care of Kansas, Inc.

8320 Ward Pkwy.

Kansas City, MO 64114

(866) 795-3995

(866) 795-3992 (fax)

sburke@cvty.com

\section{DEPARTMENT OF VETERANS AFFAIRS MEDICAL CENTER}

Pharmacy Practice-primary care emphasis

Accredited: ASHP

Length of Program: 12 months

Number of Positions: 3

Affiliation: None

Application Deadline: January 13

Starting Date: July 1

Estimated Stipend: $\quad \$ 35,000$ plus benefits

Onsite Interview: Yes
Educational/Special Requirements: PharmD or equivalent experience

Fringe Benefits: Vacation, paid holidays, sick days, and administrative time off for selected meetings

Special Features: ASHP-accredited pharmacy practice residency with large emphasis in direct patient care in a primary care setting. The pharmacy resident will work under a collaborative practice agreement with a medical team to facilitate achievement of therapeutic goals through evidence-based disease state management. In addition, the resident will have learning experiences in critical care, internal medicine, practice management, drug policy development, and education and teaching. Upon completion of this residency program, the pharmacy resident will have achieved a variety of advanced practice skills that will enable the graduate to feel confident to function effectively in multiple health care environments and roles.

Contact Information:

Jo-Ann Caudill

Residency Program Director

Dept. of Veterans Affairs Medical Center

3200 Vine St.

Cincinnati, $\mathrm{OH} 45220$

(513) 475-6322

(513) 475-6981 (fax)

Jo-Ann.Caudill@med.va.gov

\section{GROUP HEALTH COOPERATIVE}

\section{Managed Care Pharmacy Practice}

Accredited: AMCP/ASHP

Length of Program: 12 months

Number of Positions: 2

Affiliation: None

Application Deadline: January 10

Starting Date: July 1

Estimated Stipend: $\quad \$ 40,000$

Onsite Interview: Yes

Educational/Special Requirements: PharmD or equivalent

experience.

Fringe Benefits: Full medical coverage ( $\$ 35 /$ month paid by the employee) and dental coverage (cost varies depending on the plan chosen by employee) for the resident, 7 days of vacation; paid registration and some fees to attend professional meetings is provided

Special Features: The residents are trained in the role of the pharmacist in the development and implementation of clinical practice guidelines, formulary development and management, and drug use policy development. In addition, residents are trained to function as leaders in implementing pharmaceutical care plans for specific patients in a managed care setting.

Contact Information:

Jim Carlson 
Director, Pharmacy Administration

Group Health Cooperative

12400 E. Marginal Way S.

Seattle, WA 98168

(206) $901-4420$

(206) $901-4410$ (fax)

carlson.j@ghc.org

Web: http://www.ghc.org/about_gh/employ/rxresidency.jhtml

\section{HARVARD VANGUARD MEDICAL ASSOCIATES}

\section{Pharmacy Practice with Emphasis in Managed Care}

Accredited: ASHP

Length of Program: 12 months

Number of Positions: 1

Affiliation: Massachusetts College of Pharmacy and Health Sciences

Application Deadline: January 15

Starting Date: July 1

Estimated Stipend: $\quad \$ 32,000$

Onsite Interview: Yes

Educational/Special Requirements: BS in pharmacy or

PharmD

Fringe Benefits: Comprehensive medical plan, 2 weeks paid vacation

Special Features: Academic appointment: instructor of pharmacy practice

Contact Information:

William McCloskey

Massachusetts College of Pharmacy \& Health Sciences

179 Longwood Ave.

Boston, MA 02115

(617) $732-2167$

(617) $732-2244$ (fax)

william.mccloskey@bos.mcphs.edu

Web: http://www.mcphs.edu

\section{HEALTHPARTNERS}

\section{Managed Care Pharmacy}

Accredited: No

Length of Program: 12 months

Number of Positions: 1

Affiliation: None

Application Deadline: January 15

Starting Date: July 1

Estimated Stipend: Competitive

Onsite Interview: Yes

Educational/Special Requirements: PharmD

Fringe Benefits: Health insurance, vacation, and holidays

Special Features: Travel/registration for 1 national meeting

\author{
Contact Information: \\ Vyvy Vo \\ Clinical Pharmacy Program Manager \\ HealthPartners \\ 8100 34th Ave. South \\ PO Box 1309 \\ Minneapolis, MN 55440 \\ (952) 967-5133 \\ (952) 883-5875 (fax) \\ vyvy.k.vo@healthpartners.com
}

\section{HENRY FORD HEALTH SYSTEM}

Managed Care Pharmacy

Accredited: AMCP/ASHP

Length of Program: 12 months

Number of Positions: 1

Affiliation: None

Application Deadline: February 15

Starting Date: July 1

Estimated Stipend: Competitive

Onsite Interview: Yes

Educational/Special Requirements: PharmD, pharmacy practice residency desirable

Fringe Benefits: Health care, 2 weeks paid vacation, travel to 1 meeting

Special Features: The resident will design system enhancements and participate in ongoing utilization management, disease management, and compliance intervention programs. He/she will participate in formulary management and design clinical indications of effectiveness for guidelines. The resident will formulate and answer a research question, using scientific principles, with a strong emphasis on outcomes, pharmacoeconomics, and quality-of-life research. Experiences will include exposure to our HMO (Health Alliance Plan) and involvement with the Center for Clinical Effectiveness, health system studies, quality improvement center, and clinical pharmacy services. Direct patient care responsibilities in one of our ambulatory clinics will be ongoing throughout the year.

Contact Information:

Vanita Pindolia

VP, Pharmacy Care Management

Henry Ford Health System

30100 Telegraph Rd., Suite 200

Bingham Farms, MI 48025

(248) 723-0206

(248) 642-6094 (fax)

vpindoli@hapcorp.org 
HORIZON NJ HEALTH

\section{Managed Care Pharmacy}

Accredited: $\quad$ No

Length of Program: 12 months

Number of Positions: 1

Affiliation: Horizon BC

Application Deadline: February 1

Starting Date: July 1

Estimated Stipend: $\quad \$ 35,000$

Onsite Interview: Yes

Educational/Special Requirements: PharmD or equivalent experience; eligibility for New Jersey state licensure

Fringe Benefits: Paid vacation, full medical/dental/retirement benefits

Special Features: Medicaid managed care $\mathrm{HMO}$, unique focus on government programs, pharmacy case management, formulary and disease state management, development of clinical policies, outcomes research, assist with PharmD student oversight, ambulatory care experience, professional development courses, attendance to at least 1 national conference

Contact Information:

Samuel Currie

Director, Clinical Pharmacy Programs

Horizon NJ Health

210 Silvia St.

West Trenton, NJ 08628

(609) 538-0700

(609) 538-1698 (fax)

samuel_currie@horizonnjhealth.com

HUMANA INC.

Managed Care Pharmacy

Accredited: AMCP/ASHP

Length of Program: 12 months

Number of Positions: 2

Affiliation: None

Application Deadline: January 6

Starting Date: July 1

Estimated Stipend: $\quad \$ 37,000$

Onsite Interview: Yes

Educational/Special Requirements: Graduate of an accredited school of pharmacy, PharmD preferred, minimum GPA of 3.2 (on a 4.0 scale), and eligibility for pharmacy licensure

Fringe Benefits: Health, dental, 401(k), 3 weeks vacation, 2 floating holidays, relocation allowance, and travel expenses paid for 2 professional meetings

Special Features: Humana Inc. has a broad. range of programming within the pharmacy management department. The residency will offer exposure to various aspects of managed care pharmacy as well as direct patient care through clinical rotations at the Veterans Affairs hospital. The residency will offer participation in corporate pharmacy and therapeutics committees, manufacturer relations, pharmaceutical contracting and rebating, pharmacy benefit design, consumer relations, legislative and drug policy issues relating to managed care and health benefit design, ePharmacy initiatives, and outcomes analysis.

Contact Information:

Jane Stacy

Clinical Advisor

Humana Inc.

500 W. Main St., 16th Fl.

Louisville, KY 40202

(502) 580-1591

(502) 508-1591 (fax)

jstacy1@humana.com

\section{IBA HEALTH PLANS/BLUE CARE NETWORK}

Managed Care Pharmacy

Accredited:

AMCP/ASHP

Length of Program: 12 months

Number of Positions: 1

Affiliation: $\quad$ Ferris State University/Kalamazoo

Center for Medical Studies/Pfizer

Application Deadline: January 15

Starting Date: July 1

Estimated Stipend: $\quad \$ 32,000$

Onsite Interview: Yes

Educational/Special Requirements: PharmD

Fringe Benefits: Health/dental, insurance, 2 weeks vacation, paid holidays

Special Features: Travel/registration reimbursement for 1 national conference and the Great Lakes Residency Conference (pharmacy residents conference); no weekend or evening shifts Contact Information:

Teresa Klepser

Residency Director

MSU-KCMS/Ferris

1000 Oakland Dr.

Kalamazoo, MI 49008

(269) 337-6392

(269) 337-4474 (fax)

klepser@kcms.msu.edu

INTERMOUNTAIN HEALTH CARE (IHC) HEALTH PLANS Managed Care Pharmacy Practice

Accredited: $\quad$ Anticipated, July 2005

Length of Program: 1 year

Number of Positions: 1

Affiliation: None

Application Deadline: January 10

Starting Date: June 30 
Estimated Stipend: $\quad \$ 40,000$

Onsite Interview: Required

Educational/Special Requirements: Candidates must graduate from an ACPE-accredited pharmacy program with a doctor of pharmacy degree with a minimum GPA of 3.0 on a 4.0 scale. Candidate must obtain Utah pharmacist licensure within the first 60 days of the program.

Fringe Benefits: Health, dental, and life insurance; staff discounts; 10 days of vacation leave; and 10 holidays

Special Features: Travel benefits to either the ASHP Midyear Clinical Meeting or the AMCP Educational Meeting and the Western States Conference

Contact Information:

Jeffrey Dunn

Formulary and Contract Manager

IHC Health Plans

4646 W. Lake Park Blvd., Suite N3

Salt Lake City, UT 84120

(801) 442-7984

(801) 442-3006 (fax)

jeffrey.dunn@ihc.com

\section{KAISER PERMANENTE}

\section{Managed Care}

\section{Accredited: No}

Length of Program: 12 months

Number of Positions: 2

Affiliation: None

Application Deadline: January 1

Starting Date: July 1

Estimated Stipend: $\quad \$ 41,220$ (2005-2006)

Onsite Interview: Yes

Educational/Special Requirements: This is a specialty residency in managed care with emphasis on pharmacy practice management; BS/PharmD

Fringe Benefits: Medical benefits, 10 days sick leave/vacation, 5 holidays, $\$ 500$ for national meeting plus expenses paid for Western States Residency Conference

Special Features: Emphasis in administration/practice management

Contact Information:

Susan Downard

Area Pharmacy Manager

Kaiser Permanente

16601 E. Centretech Pkwy.

Aurora, CO 80011

(303) 326-6764

(303) $739-3574$ (fax)

Susan.L.Downard@kp.org

\section{KAISER PERMANENTE}

Mental Health (Specialty)

Accredited: No

Length of Program: 12 months

Number of Positions: 1

Affiliation: None

Application Deadline: January 1

Starting Date: July 5

Estimated Stipend: $\quad \$ 41,220(2005-2006)$

Onsite Interview: Yes

Educational/Special Requirements: PharmD required; completion of pharmacy practice residency or possession of equivalent clinical experience preferred

Fringe Benefits: Health insurance, holidays, travel assistance

Special Features: Group-model HMO setting

Contact Information:

Daniel Dugan

Clinical Pharmacy Specialist in Mental Health

Kaiser Permanente of Colorado

16601 E Centretech Pkwy.

Aurora, CO 80011

(303) 467-5776

(303) 467-5805 (fax)

daniel.j.dugan@kp.org

\section{KAISER PERMANENTE}

Primary Care (Specialty)

Accredited: No

Length of Program: 12 months

Number of Positions: 2

Affiliation: None

Application Deadline: January 1

Starting Date: July 5

Estimated Stipend: $\quad \$ 41,220$ (2005-2006)

Onsite Interview: Yes

Educational/Special Requirements: PharmD required; completion of pharmacy practice residency or possession of equivalent clinical experience preferred

Fringe Benefits: Health insurance, holidays, travel assistance

Special Features: Group-model HMO setting

Contact Information:

Rachana Patel

Clinical Pharmacy Specialist

Kaiser Permanente

1375 East 20th Ave.

Denver, CO 80205

(303) $764-4479$

(303) 861-3668 (fax)

rachana.j.patel@kp.org 
[This listing has not been not updated; contact the program for current information.]

\section{KAISER PERMANENTE MEDICAL CARE PROGRAM- CALIFORNIA}

\section{Pharmacy Practice and Drug Information Practice}

Accredited: ASHP

Length of Program: 12 months

Number of Positions: 26

Affiliation: None

Application Deadline: January 15

Starting Date: July 1

Estimated Stipend: $\quad \$ 35,000$

Onsite Interview: Yes

Educational/Special Requirements: Applicants must be a graduate of an accredited college of pharmacy and be licensed, or be eligible for licensure, in California. Good communication skills required. Resident will develop a project with targeted care outcomes and present at the annual Western States Conference.

Fringe Benefits: Medical, dental, and optical insurance; holidays; vacation/sick leave

Special Features: Hospital and ambulatory care experiences in the nation's largest health maintenance organization, preventative and disease state management in an integrated managed care setting

\section{Contact Information:}

Elaine Watanabe

Pharmacy Services Manager, Recruitment

Kaiser Permanente Pharmacy Operations Services,

California Division

9521 Dalen St.

Downey, CA 90242

(714) $796-4809$

(714) 796-4826 (fax)

Elaine.G.Watanabe@kp.org

KAISER PERMANENTE MEDICAL CARE PROGRAMINLAND EMPIRE SERVICE AREA

\section{General Pharmacy Practice}

Accredited: ASHP

Length of Program: 12 months

Number of Positions: 2

Affiliation: None

Application Deadline: January 15

Starting Date: July 1

Estimated Stipend: $\quad \$ 35,000$

Onsite Interview: Yes

Educational/Special Requirements: Graduate of an accredited college of pharmacy and be licensed, or be eligibile for licensure, in California; pharmacy school transcript; 3 letters of recommendation; letter of intent; and curriculum vitae
Fringe Benefits: 2 weeks paid vacation; health benefits, including dental/optical; paid holidays; office space; reimbursement for off-site experiences

Special Features: Kaiser Permanente is the nation's largest nonprofit health plan, serving more than 8.4 million members in 9 states. The Inland Empire Service Area consists of 2 medical centers and 14 satellite medical offices for 598,000 members in the San Bernardino and Riverside counties of southern California.

Contact Information:

Patricia Gray

Clinical Operations Manager

Kaiser Permanente Inland Empire Service Area

9310 Sierra Ave.

Fontana, CA 92335

(909) 427-3838

(909) 427-3830 (fax)

patricia.l.gray@kp.org

KAISER PERMANENTE MEDICAL CARE PROGRAMLOS ANGELES MEDICAL CENTER

\section{Pharmacy Practice}

Accredited: ASHP

Length of Program: 12 months

Number of Positions: 1

Affiliation: None

Application Deadline: January 10

Starting Date: July 1

Estimated Stipend: $\quad \$ 35,000$

Onsite Interview: Yes

Educational/Special Requirements: Applicants must be a graduate of an accredited college of pharmacy and be licensed, or be eligible for licensure, in California. Good communication skills required. Resident will develop a project with targeted care outcomes and present at the annual Western States Conference.

Fringe Benefits: Medical, dental, optical insurance; holidays; vacation/sick leave

Special Features: The Kaiser Permanente Los Angeles Medical Center is the tertiary care center for Kaiser Permanente in southern California and provides comprehensive inpatient, outpatient, and ambulatory care services to Kaiser Permanente members. This residency program provides development and training for recently graduated pharmacists, with an emphasis on pharmaceutical care and leadership to a diverse community. This program will allow the residents to become familiar with pharmacy practice in an integrated health care program.

Contact Information:

Steve Litsey

Pharmacy Leader-Metro Service Area

Kaiser Permanente Pharmacy Operations Services 
1515 N. Vermont Ave., Suite 237

Los Angeles, CA 90027

(323) 783-8306

(323) 783-7609 (fax)

toni.a.rodriguez@kp.org

KAISER PERMANENTE MEDICAL CARE PROGRAMMETRO LOS ANGELES

\section{Managed Care}

Accredited: Yes

Length of Program: 12

Number of Positions: 2

Affiliation: None

Application Deadline: January 10

Starting Date: July 1

Estimated Stipend: $\quad 35,000$

Onsite Interview: Yes

Educational/Special Requirements: Applicants must be a graduate of an accredited college of pharmacy and be licensed, or be eligible for licensure, in California. Good communication skills required. Resident will develop a project with targeted care outcomes and present at the annual Western States Conference.

Fringe Benefits: Paid insurance (medical, dental, vision), holidays, vacation/sick days

Special Features: The Kaiser Permanente Los Angeles Medical Center is the tertiary care center for Kaiser Permanente in southern California and provides comprehensive inpatient, outpatient, and ambulatory care services to Kaiser Permanente members. This residency program provides development and training for recently graduated pharmacists, with an emphasis on pharmaceutical care and leadership to a diverse community. This program will allow the residents to become familiar with managed care pharmacy practice in an integrated health care program.

Contact Information:

Elizabeth Oyekan, PharmD

Residency Progam Coordinator

Kaiser Permanente Medical Care Program-Metro Los Angeles

Pharmacy Operations

1515 N. Vermont Ave., Suite 237

Los Angeles, CA 90027

(323) 783-8306

(323) 783-7609 (fax)

elizabeth.a.oyekan@kp.org
KAISER PERMANENTE MEDICAL CARE PROGRAMTRI-CENTRAL SERVICE AREA

$\begin{array}{ll}\text { Managed Care Organization } \\ \text { Accredited: } & \text { ASHP } \\ \text { Length of Program: } & 1 \text { year } \\ \text { Number of Positions: } & 2 \\ \text { Affiliation: } & \text { None } \\ \text { Application Deadline: } & \text { January } 9 \\ \text { Starting Date: } & \text { July } 1 \\ \text { Estimated Stipend: } & \$ 35,000 \\ \text { Onsite Interview: } & \text { Yes }\end{array}$

Educational/Special Requirements: Recent graduate of an accredited school of pharmacy and eligibility for California licensure, college transcript(s), letter of intent, 3 letters of recommendation, and curriculum vitae

Fringe Benefits: 2 weeks paid vacation; 6 paid holidays; sick leave; health benefits, including dental/optical (also dependents); uniforms; office space; and reimbursement for off-site experiences

Special Features: The program provides the resident with an opportunity to participate in the provision of health care in a large managed care environment. Resident will gain experience in various practice areas: acute care, ambulatory care, physician drug education, drug information, outpatient pharmacy, and practice management; ambulatory care practice includes anticoagulation, heart failure, hypertension, integrated CVD, oncology, etc. Residents completing our program will have a strong foundation for future pharmacy practice.

\section{Contact Information:}

John Sie

Pharmacy Practice Residency Coordinator, Ambulatory Care Clinical Pharmacy Services Supervisor

Kaiser Permanente Medical Care Program Tri-Central Service

Area, Pharmacy Operations

1011 Baldwin Park Blvd.

Baldwin Park, CA 90706

(626) 851-5602

(626) 851-5813 (fax)

john.l.sie@kp.org

KAISER PERMANENTE MEDICAL CARE PROGRAMWEST LOS ANGELES

Pharmacy Practice

Accredited: ASHP

Length of Program: 12 months

Number of Positions: 1

Affiliation: None

Application Deadline: January 15

Starting Date: July 1

Estimated Stipend: $\quad \$ 35,000$

Onsite Interview: Yes 
Educational/Special Requirements: Applicants must be a graduate of an accredited college of pharmacy and be licensed, or be eligible for licensure, in California. Good communication skills required. Resident will develop a project with targeted care outcomes and present at the annual Western States Conference

Fringe Benefits: Medical, dental, and optical insurance; holidays; vacation/sick leave

Special Features: Hospital and ambulatory care experiences in the nation's largest integrated care organization, preventative and disease state management in an integrated managed care setting. Flexible program molded to the resident's interests.

Contact Information:

Michael Cinnamond, PharmD

Inpatient Pharmacy Director, Residency Program Director

Kaiser Permanente Medical Care Program at West Los Angeles

6041 Cadillac Ave., B 310

Los Angeles, CA 90034

(323) $857-2044$

(323) 857-2870 (fax)

michael.d.cinnamond@kp.org

\section{KAISER PERMANENTE MID-ATLANTIC STATES REGION}

\section{Managed Care Pharmacy}

$\begin{array}{ll}\text { Accredited: } & \text { AMCP/ASHP } \\ \text { Length of Program: } & 12 \text { months } \\ \text { Number of Positions: } & 2 \\ \text { Affiliation: } & \text { None } \\ \text { Application Deadline: January } 6 \\ \text { Starting Date: } & \text { July } 5 \\ \text { Estimated Stipend: } & \$ 39,500 \\ \text { Onsite Interview: } & \text { Yes }\end{array}$

Educational/Special Requirements: PharmD preferred, pharmacy licensure eligibility in DC, Maryland, or Virginia

Fringe Benefits: Medical benefits, selected holidays, sick, vacation and education leave for Midyear Clinical Meeting and Eastern States Conference

Special Features: In addition to helping develop new and innovative programs, the resident will participate on the Pharmacy \& Therapeutics Committee, teach patient education classes, provide pharmacy staff continuing education, assist in educating pharmacy students, and complete residency projects and presentations.

Contact Information:

Katrin Fulginiti

Director, Managed Care Pharmacy Practice Residency Program

Kaiser Permanente-Mid-Atlantic

12201 Plum Orchard Dr.

Silver Spring, MD 20904

(301) $572-3330$

(301) 572-3399 (fax) katrin.fulginiti@kp.org

Web: http://www.kaiserpermanente.org

KAISER PERMANENTE OF CALIFORNIASPECIALTY RESIDENCY IN DRUG INFORMATION

Medical Care/Drug Information

Accredited: ASHP

Length of Program: 12 months

Number of Positions: 2

Affiliation: None

Application Deadline: March 31

Starting Date: July 1

Estimated Stipend: $\quad \$ 70,000$

Onsite Interview: Yes

Educational/Special Requirements: PharmD, pharmacy practice residency program or equivalent experience, excellent communication skills, eligibility for California licensure, 3 letters of recommendation

Fringe Benefits: Medical, dental, optical insurance; 10 days time off; attendance at 1 pharmacy conference

Special Features: None

Contact Information:

Mirta Millares

Kaiser Permanente

12254 Bellflower Blvd., Suite 106

Downey, CA 90242

(562) 658-3630

(562) 658-3758 (fax)

mirta.millares@kp.org

\section{KAISER PERMANENTE OF COLORADO}

\section{Cardiology/Managed Care}

Accredited: No

Length of Program: 12 months

Number of Positions: 3

Affiliation: None

Application Deadline: January 1

Starting Date: July 1

Estimated Stipend: $\quad \$ 41,220$

Onsite Interview: Yes

Educational/Special Requirements: PharmD required; prior pharmacy practice residency or equivalent preferred

Fringe Benefits: Health benefits, travel support to ASHP Midyear meeting and Western States Residency Conference Special Features: This cardiology specialty residency provides unique opportunities to acquire advanced knowledge and skills in ambulatory management of anticoagulation, cardiac risk reduction, and heart failure in a managed care setting. Numerous educational opportunities exist. Experience in evaluating clinical and financial outcomes will be emphasized. 
Completion of a residency research project required.

Contact Information:

Anne Denham, PharmD

Clinical Pharmacy Specialist

Kaiser Permanente of Colorado

Clinical Pharmacy Cardiac Risk Service

16601 E Centretech Pkwy.

Aurora, CO 80011

(303) 326-7663

(303) 326-7670 (fax)

anne.denham@kp.org

\section{KAISER PERMANENTE OF COLORADO}

\section{Mental Health/Managed Care}

Accredited: No

Length of Program: 12 months

Number of Positions: 1

Affiliation: None

Application Deadline: January 1

Starting Date: July 1

Estimated Stipend: $\quad \$ 41,220$

Onsite Interview: Yes

Educational/Special Requirements: PharmD required, prior pharmacy practice residency or equivalent practical experience preferred

Fringe Benefits: Health benefits, travel support to ASHP Midyear Clinical Meeting and Western States Residency Conference

Special Features: Experiences include inpatient and outpatient psychiatric pharmacy practice sites among a full range of behavioral health conditions as well as neurology and chemical dependence. Evaluation of clinical outcomes is emphasized and completion of residency research is required.

\section{Contact Information:}

Daniel Dugan

Clinical Pharmacy Specialist in Mental Health

Kaiser Permanente of Colorado

16601 E Centretech Pkwy.

Aurora, CO 80011

(303) 467-5776

(303) 467-5805 (fax)

daniel.j.dugan@kp.org

\section{KAISER PERMANENTE OF COLORADO}

\section{Primary Care/Managed Care}

Accredited: No

Length of Program: 12 months

Number of Positions: 3

Affiliation: None

Application Deadline: January 1
Starting Date: July 1

Estimated Stipend: $\quad \$ 41,220$

Onsite Interview: Yes

Educational/Special Requirements: PharmD required; prior pharmacy practice residency or equivalent experience preferred Fringe Benefits: Health benefits, travel support to ASHP Midyear Clinical Meeting and Western States Residency Conference

Special Features: This primary care/managed care specialty residency provides the unique opportunity to acquire advanced knowledge and skills in ambulatory care pharmacotherapy in a managed care setting. Practice sites include primary care clinics, centralized services (anti-coagulation, cardiac risk), and specialty services (diabetes, cardiology, infectious disease, mental health, nephrology). Residents participate in formulary management, pharmacoeconomic evaluations, and target drug programs. Numerous educational opportunities exist. Experience in evaluating clinical and financial outcomes will be emphasized. Completion of residency research project required.

Contact Information:

Rachana Patel

Clinical Pharmacy Specialist

Kaiser Permanente

1375 East 20th Ave.

Denver, CO 80205

(303) 764-4479

(303) 861-3668 (fax)

rachana.j.patel@kp.org

\section{KAISER PERMANENTE OF GEORGIA}

\section{Managed Care Pharmacy Practice}

Accredited: AMCP/ASHP

Length of Program: 12 months

Number of Positions: 2

Affiliation: None

Application Deadline: January 13

Starting Date: July 1

Estimated Stipend: $\quad \$ 34,000$

Onsite Interview: Yes

Educational/Special Requirements: PharmD preferred; eligibility for Georgia licensure

Fringe Benefits: Medical/dental/vision insurance, holidays, vacation/ sick leave

Special Features: Ambulatory care, acute care, drug information, and administration

Contact Information:

Suzanne Booth

Residency Program Coordinator

Kaiser Permanente

200 Crescent Centre Pkwy.

Tucker, GA 30083 
(770) 496-3653

(770) 496-3487 (fax)

suzanne.booth@kp.org

\section{KELSEY-SEYBOLD CLINIC/UNIVERSITY OF HOUSTON}

Pharmacy Practice with an Emphasis on Managed Care

Accredited: ASHP/AMCP

Length of Program: 1 year

Number of Positions: 2

Affiliation: University of Houston

Application Deadline: January 5

Starting Date: July 1

Estimated Stipend: $\quad 30,000$

Onsite Interview: Yes

Educational/Special Requirements: PharmD or equivalent expe-

rience

Fringe Benefits: State of Texas benefits, 10 days vacation, support to attend AMCP, ASHP, TSHP, and either Alcalde or Mid-West Residency Conference

Special Features: Ambulatory-care-focused administrative and clinical responsibilities, collaborations with other $\mathrm{UH}$ residents

Contact Information:

Sarah Lake-Wallace, PharmD

Kelsey-Seybold Clinic

Pharmacy Administration

8900 Lakes at 610 Dr.

Houston, TX 77054

(713) $442-6248$

(713) 442-5253 (fax)

slwallace@kelsey-seybold.com

\section{MEDCO HEALTH SOLUTIONS, INC.}

\section{Managed Care Pharmacy}

Accredited:

AMCP/ASHP

Length of Program: 12 months

Number of Positions: 2

Affiliation: None

Application Deadline: January 5

Starting Date: June 26

Estimated Stipend: $\quad \$ 34,000$

Onsite Interview: Yes

Educational/Special Requirements: PharmD degree, eligibility for New Jersey licensure, managed care rotation or experience preferred

Fringe Benefits: Complete medical coverage, paid holidays and vacation

Special Features: Professional development trainings, travel and attendance at educational meetings

\author{
Contact Information: \\ Doris Fishman \\ Senior Director, Clinical Therapeutics \\ Medco Health Solutions, Inc. \\ 100 Parsons Pond Dr. \\ Mail Stop F2-3 \\ Franklin Lakes, NJ 07417 \\ (201) 269-6159 \\ (201) 260-1035 (fax) \\ MedcoRProg@medcohealth.com
}

\section{NOVARTIS PHARMACEUTICALS CORPORATION}

Health Economics \& Outcomes Research Fellowship

Accredited:

No

Length of Program: 2 years (Rutgers site, flexible)

Number of Positions: 3

Affiliation

Duke University; Scott \& White

Health Plan/University of Texas at

Austin; Rutgers University

Application Deadline: December 31

Starting Date: July 1

Estimated Stipend: $\quad \$ 35,000-\$ 44,000$

Onsite Interview: Yes

Educational/Special Requirements: Advanced degree in health services research, public health, health policy, pharmacy, economics, medicine, or other related areas, with some experience in outcomes research

Fringe Benefits: Medical insurance, vacation

Special Features: The fellows will gain familiarity with outcomes research principles/application and experience in designing research studies that examine economic, clinical, and humanistic outcomes. The first year is spent at an academic/managed care institution and the second year with Novartis's Health Economics \& Outcomes Research Department.

Contact Information:

Feride Frech

Director, Health Economics \& Outcomes Research

Novartis Pharmaceuticals Corporation

One Health Plaza

East Hanover, NJ 07936-1080

(862) 778-5094

(973) 781-3018 (fax)

feride.frech@novartis.com

\section{OPTIMA HEALTH PLAN/ SENTARA HEALTHCARE}

Managed Care

Accredited:

Not at this time

Length of Program: 12 months

Number of Positions: 1

Affiliation: None 
Application Deadline: February 15

Starting Date: July 1

Estimated Stipend: $\quad \$ 31,720$

Onsite Interview: Yes

Educational/Special Requirements: PharmD from an accredited school of pharmacy or equivalent experience, onsite interview, and eligibility for Virginia licensure

Fringe Benefits: 2 weeks of paid vacation and uninterrupted stipend during minor illness, a health insurance plan, travel assistance for continuing education events and other professional activities

Special Features: Resident will have exposure to an integrated health care system and system-wide pharmacy services, including a drug information center. The resident will have the opportunity to precept students from Virginia Commonwealth University and Hampton University schools of pharmacy and work with medical residents from the Eastern Virginia Medical School.

Contact Information:

Elizabeth Brusig, PharmD

Clinical Pharmacist

Optima Health Plan

4417 Corporation Lane

Virginia Beach, VA 23464

(757) $552-7519$

(757) $552-7516$ (fax)

elbrusig@sentara.com

ORTHO-MCNEIL JANSSEN SCIENTIFIC AFFAIRS, LLC

\section{Drug Information}

Accredited: No

Length of Program: 12 months

Number of Positions: 2

Affiliation: None

Application Deadline: December 31

Starting Date: July 1

Estimated Stipend: Competitive

Onsite Interview: Yes

Educational/Special Requirements: Contact program

Fringe Benefits: Contact program

Special Features: Contact program

Contact Information:

Will Zachok

Associate Director, Medical Communications

Ortho-McNeil Janssen Scientific Affairs, LLC

1000 Route 202 S

Raritan, NJ 08869

(908) 218-6283

(908) 722-6402 (fax)

wzachok@ompus.jnj.com

\section{ORTHO-MCNEIL JANSSEN SCIENTIFIC AFFAIRS, LLC}

Pharmaceutical Industry, Department of Outcomes Research

Accredited: No

Length of Program: 24 months

Number of Positions: 1

Affiliation: Thomas Jefferson University

Application Deadline: December 31

Starting Date: June 2006 (flexible)

Estimated Stipend: Competitive

Onsite Interview: Yes

Educational/Special Requirements: Contact program

Fringe Benefits: Contact program

Special Features: Fellows spend the first year of the program working on outcomes research projects in an academic setting and the second year in the pharmaceutical industry. Fellows have the opportunity to take coursework in biostatistics, epidemiology, economics, and other outcomes-related subjects.

Contact Information:

Julie Locklear, PharmD, MBA

Associate Director, Outcomes Research

Ortho-McNeil Janssen Scientific Affairs, LLC

1125 Trenton-Harbourton Rd.

Titusville, NJ 08560

(609) $730-3664$

(609) $730-2556$ (fax)

jlockle1@janus.jnj.com

OUTCOMES PHARMACEUTICAL HEALTH CARE

Medication Therapy Management Firm

Accredited: ASHP/AMCP

Length of Program: 1 year

Number of Positions: 1

Affiliation: University of Iowa

Application Deadline: December 31

Starting Date: July 5

Estimated Stipend: $\quad \$ 33,000$

Onsite Interview: Yes

Educational/Special Requirements: Candidates for residency must possess a doctor of pharmacy degree from a school of pharmacy accredited by the American Council on Pharmaceutical Education (ACPE) and be eligible for licensure in Iowa.

Fringe Benefits: For additional information, contact the Outcomes office at (515) 237-0001 or info@getoutcomes.com. Special Features: Outcomes' clinical services residency is a 12 -month managed care systems residency program. This residency offers a unique learning experience on how pharmacists can impact the quality and rising cost of health care by providing patient-oriented, care-based services. Residency activities include account management, marketing and communications, pharmacoeconomic data collection and analysis, claims assessment, development and implementation of disease management 
programs, development and administration of research projects, and training of pharmacists and support staff. The resident also serves as a preceptor to PharmD clerkship students.

\section{Contact Information:}

Patty Kumbera

Chief Operations Officer

Outcomes Pharmaceutical Health Care

601 E. Locust, Suite 200

Des Moines, IA 50309

(515) 237-0001

(515) 237-0002 (fax)

pkumbera@getoutcomes.com

Web: http://www.getoutcomes.com

\section{PHARMACARE}

\section{Pharmacy Benefits Management}

\section{Accredited: No}

Length of Program: 12 months

Number of Positions: 1

Affiliation: $\quad$ University of Pittsburgh School of Pharmacy

Application Deadline: January 12

Starting Date: July 1

Estimated Stipend: $\quad \$ 31,000$

Onsite Interview: Yes

Educational/Special Requirements: PharmD

Fringe Benefits: Comprehensive benefits package, no weekends/holidays, attend professional managed care meetings

Special Features: The University of Pittsburgh School of Pharmacy and EHS, one of the nation's largest pharmacy chainbased prescription management firms, offers an opportunity to practice in a dynamic PBM environment and gain a clinical and administrative perspective in managed pharmacy benefit plans for a wide variety of clients. Multifaceted experience will include DUR criteria development, clinical intervention activities, P\&T activities, clinical systems development, and new business development/client services/ marketing support.

\section{Contact Information:}

Teddi Gianangeli

Senior Clinical Management Specialist

Pharmacare

620 Epsilon Dr.

Pittsburgh, PA 15238

(412) 967-2300 ext. 5045

(412) 968-2676 (fax)

tgianangeli@pharmacare.com
[This listing has not been not updated; contact the program for current information.]

\section{PHARMACEUTICAL CARE NETWORK}

Managed Care Pharmacy Practice

Accredited: $\quad$ No

Length of Program: 12 months

Number of Positions: 1

Affiliation: None

Application Deadline: January 15

Starting Date: July 1

Estimated Stipend: $\quad \$ 37,500$

Onsite Interview: Yes

Educational/Special Requirements: Graduate of an accredited college of pharmacy and licensed, or be eligible for licensure, in California

Fringe Benefits: Paid vacation and sick leave, health/dental/ vision benefits, and educational support to attend professional meetings

Special Features: This residency will provide training in formulary management, provider drug therapy education, drug benefit design, outcomes analysis, and prior authorization. The resident will participate in drug utilization review, P\&T committee presentations, and interface with pharmacists from a variety of professional fields. The resident will learn to use PCN's MedIntelligence software to identify drug therapy problems and make appropriate interventions. This program includes rotations in direct patient care and drug information and an opportunity to rotate through the California Pharmacists Association.

\section{Contact Information:}

Philip Parsatoon

Vice President, Professional Services

Pharmaceutical Care Network

9343 Tech Center Dr., Suite 200

Sacramento, CA 95826-2563

(916) 361-4450

(916) 414-4650 (fax)

resident@pharmcarenet.com

\section{- PHARMACY MANAGEMENT CONSULTANTS/ OKLAHOMA UNIVERSITY}

Managed Care Pharmacy

Accredited:

ASHP-Managed Care Pharmacy

Systems

Length of Program: 12 months

Number of Positions: 1

Affiliation:

Oklahoma University College of

Pharmacy

Application Deadline: February 1

Starting Date: July 1

Estimated Stipend: $\$ 35,000$

Onsite Interview: Preferred 
Educational/Special Requirements: Pharmacy degree

Fringe Benefits: 10 days vacation, health and dental coverage, faculty appointment at the level of clinical instructor, sponsorship to at least 1 professional meeting

Special Features: Evaluate health plan formularies, develop clinical guidelines, evaluate retrospective and prospective DUR criteria, develop educational intervention programs, serve as preceptor for pharmacy students; program includes experience working with dual Medicare/Medicaid eligibles and with the state PDP plan.

\section{Contact Information:}

Elgene Jacobs

Pharmacy Management Consultants

1122 N.E. 13th St.

ORI W-4403

Oklahoma City, OK 73117

(405) 271-9039, ext. 47354

(405) 271-2615 (fax)

elgene-jacobs@ouhsc.edu

\section{PRESCRIPTION SOLUTIONS}

\section{Managed Care}

Accredited: ASHP

Length of Program: 12 months

Number of Positions: 1 or 2

Affiliation: None

Application Deadline: January 7

Starting Date: July 5

Estimated Stipend: $\quad \$ 40,000$

Onsite Interview: Yes

Educational/Special Requirements: PharmD, license to practice in California

Fringe Benefits: 2 weeks paid vacation, paid holidays, sick days, travel reimbursement

Special Features: Drug therapy management, developing clinical guidelines for appropriate drug use, formulary management, legal and regulatory affairs; professional meetings and seminars: required to attend the ASHP Midyear Clinical Meeting, CSHP Seminar, AMCP Educational Conference, and Western States Conference

Contact Information:

Alex Gilderman

Director, Clinical Pharmacy Services

clo Prescription Solutions

3515 Harbor Blvd.

Costa Mesa, CA 92626

(714) 825-6768

(714) 825-3742 (fax)

alex.gilderman@rxsol.com
RUTGERS UNIVERSITY/HORIZON BLUE CROSS BLUE SHIELD OF NEW JERSEY

Managed Care Organization

Accredited: No

Length of Program: 12 months

Number of Positions: 2

Affiliation: $\quad$ Ernest Mario School of Pharmacy, Rutgers University, State University of New Jersey

Application Deadline: January 15

Starting Date: July 1

Estimated Stipend: $\quad \$ 30,000$

Onsite Interview: Yes

Educational/Special Requirements: PharmD, eligibility for

New Jersey state license

Fringe Benefits: Full medical coverage, dental and retirement benefits

Special Features: No weekend or staffing requirements, teaching and preceptoring, mandatory, graduate courses offered at Rutgers University, industry and PBM perspectives of managed care

Contact Information:

Saira A. Jan

Associate Professor, Rutgers University

Associate Director, Pharmacy Management

Horizon Blue Cross Blue Shield of NJ

Three Penn Plaza East, PP-13Q

Newark, NJ 07105

(973) 466-4575

(973) 466-6266 (fax)

saira_jan@horizon-bcbsnj.com

[This listing has not been not updated; contact the program for current information.]

SCOTT \& WHITE

Pharmacy Practice Managed Care

Accredited: No

Length of Program: 1 year

Number of Positions: 1

Affiliation: University of Texas at Austin

Application Deadline: February 15

Starting Date: July 1

Estimated Stipend: $\quad \$ 30,000$

Onsite Interview: Yes

Educational/Special Requirements: PharmD, eligibility for

Texas state license

Fringe Benefits: Full medical coverage and dental

Special Features: Minimal weekend staffing requirements; teaching and preceptoring, if desired; industry and PBM perspectives of managed care; marketing and sales exposure 
Contact Information:

John Jackimiec

Director of Pharmacy Managed Care

Scott \& White

2601 Thornton Lane, Suite A

Temple, TX 76502

(254) $742-3144$

(254) 742-3109 (fax)

jjackimiec@swmail.sw.org

\section{SOUTHERN ARIZONA VA HEALTH CARE SYSTEM}

\section{Pharmacy Practice}

Accredited: $\quad$ ASHP since 1982

Length of Program: 12 months

Number of Positions: 7

Affiliation:

University of Arizona

Application Deadline: January 16

Starting Date: July 1

Estimated Stipend: $\quad \$ 33,000$ plus benefits

Onsite Interview: Interview required, onsite preferred

Educational/Special Requirements: Curriculum vitae, 3 letters of recommendation, college transcripts, 1 writing sample, U.S. citizenship

Fringe Benefits: Residents accumulate 13 days of paid vacation time during the residency year. Sick leave is accrued at the rate of 4 hours every 2 weeks. Educational leave is provided to attend the Arizona Society of Health-Systems Pharmacists Annual Meeting, the ASHP Midyear Clinical Meeting, and the Western States Conference for Pharmacy Residents, Fellows, and Preceptors. Travel funds are available to offset some of the expenses for these educational meetings. Residents have access to the same medical and dental insurance plans that are offered to full-time employees of the VA. These include a wide range of $\mathrm{HMO}$ and PPO health plans. Tucson also has a wide range of outdoor activities and excellent weather year round.

Special Features: This comprehensive residency includes a balance of inpatient and outpatient clinical pharmacy experiences. Residents work in the areas of internal medicine, cardiology, neurology clinics, primary care, geriatrics, hospice, surgery/nutritional support, mental health, practice management, DUE, Pharmacy and Therapeutics Committee activities, drug literature evaluation, drug policy development, teaching, research, and enhancing communication abilities. Two months of elective experience are available.

\section{Contact Information:}

William Jones, MS, RPh

Southern Arizona Veterans Administration Health Care System

3601 South Sixth Ave.

Pharmacy Service 5-119

Tucson, AZ 85723

(520) $792-1450$, ext. 6721
(520) 629-4700 (fax)

William.Jones@med.va.gov

[This listing has not been not updated; contact the program for current information.]

UNITED DRUGS

Managed Care

Accredited: Not at this time

Length of Program: 1 year

Number of Positions: 1

Affiliation: AMCP

Application Deadline: June 15

Starting Date: September 1

Estimated Stipend: $\quad \$ 33,000$

Onsite Interview: Yes

Educational/Special Requirements: Completion from an accredited pharmacy school, PharmD preferred; ability to work independently

Fringe Benefits: Understanding of managed care from the perspective of a PBM, product development opportunities, and ability to live in Arizona for a year

Special Features: Work hours negotiable

Contact Information:

Jean Brown

Director of Clinical Services

United Drugs

7227 North 16th St., Suite 160

Phoenix, AZ 85020-5256

(602) 678-1179, ext. 229

(602) 678-0772 (fax)

brownj@uniteddrugs.com

[This listing has not been not updated: contact the program for current information.]

\section{UNIVERSITY AT BUFFALO}

\section{Ambulatory Care}

Accredited: Pending

Length of Program: 1 year

Number of Positions: 2

Affiliation: University

Application Deadline: October 1

Starting Date: January 1

Estimated Stipend: Contact program

Onsite Interview: Required

Educational/Special Requirements: PharmD or equivalent experience required

Fringe Benefits: Health, dental, vision insurance; paid vacation; conference travel funds

Special Features: Unique experience designed to further refine skills in pharmaceutical care in addition to developing skills in 
program development and personnel and resource management. Resident is involved in coordination of clinical activities in a high-volume lobby-based pharmacy and a health clinic based ambulatory care pharmacy. The resident will participate in medication histories, adherence counseling, and education programs. Development and implementation of disease management initiatives, patient education, medical informatics and supervision of PharmD students are also significant aspects of the program. This residency will allow ample latitude for the resident to explore interests and further develop skills as a practitioner. The resident will also be appointed as a clinical instructor at the University at Buffalo, School of Pharmacy and Pharmaceutical Sciences.

Contact Information:

Gene Morse, PharmD

University at Buffalo

School of Pharmacy and Pharmaceutical Sciences

311 Hochstetter Hall

Buffalo, NY 14260

(716) $645-2828$

(716) 645-2886 (fax)

emorse@buffalo.edu

UNIVERSITY OF ILLINOIS AT CHICAGO \& WALGREENS HEALTH INITIATIVES

$\begin{array}{ll}\text { Fellowship_- Outcomes Research } \\ \text { Accredited: } & \text { No } \\ \text { Length of Program: } & 2 \text { years } \\ \text { Number of Positions: } & 1 \\ \text { Affiliation: } & \text { University of Illinois \& Walgreens } \\ & \text { Health Initiatives } \\ \text { Application Deadline: } & \text { February } 1 \\ \text { Starting Date: } & \text { July } 1 \\ \text { Estimated Stipend: } & \$ 36,000\end{array}$

Onsite Interview:

Educational/Special Requirements: Applicants should have a PharmD or MD (or equivalent) and have completed a pharmacy practice or managed care residency

Fringe Benefits:

Special Features: This is a 2-year fellowship jointly offered by Walgreens Health Initiatives and the Center for Pharmacoeconomic Research at the University of Illinois at Chicago. The aim of the program is to train clinical pharmacists to conduct research in drug therapy outcomes and pharmacoeconomics in the managed care setting. Knowledge and experience will be gained in the use of research tools to evaluate economic, humanistic, and clinical outcomes of drug therapy. Presentation and publication of research findings in peer-reviewed venues is expected. The fellowship is designed to facilitate career opportunities in managed care, health provider organizations, consulting, academia, or the pharmaceutical industry.

Contact Information:

Glen Schumock, PharmD, MBA

University of Illinois at Chicago

Center for Pharmacoeconomic Research

833 S. Wood St. (MC 886)

Chicago, IL 60612

(312) 996-7961

schumock@uic.edu

UNIVERSITY OF MARYLAND SCHOOL OF PHARMACY/ CAREFIRST BLUECROSS BLUESHIELD

Managed Care Pharmacy

Accredited: No

Length of Program: 12 months

Number of Positions: 1

Affiliation: University of Maryland

Application Deadline: January 5

Starting Date: July 1

Estimated Stipend: $\quad 31,500$

Onsite Interview: Yes

Educational/Special Requirements: Graduate degree in pharmacy Fringe Benefits: Health insurance, parking, support for national meeting attendance and poster presentation

Special Features: Appointment as a clinical instructor at the University of Maryland School of Pharmacy, ambulatory care clinics at $\mathrm{HMO}$, office with computer/references at managed care organization

Contact Information:

Catherine Cooke

Clinical Assistant Professor

University of Maryland School of Pharmacy

5106 Bonnie Branch Rd.

Ellicott City, MD 21043

(410) 480-5012

(410) 480-5296 (fax)

catherine.cooke@pfizer.com

UNIVERSITY OF TEXAS MEDICAL BRANCH CORRECTIONAL MANAGED CARE

Pharmacy Practice with an Emphasis in Managed Care

Accredited: ASHP

Length of Program: 12 months

Number of Positions: 1

Affiliation: UTMB

Application Deadline: February 15

Starting Date: July 1

Estimated Stipend: Contact program

Onsite Interview: Yes

Educational/Special Requirements: Pharmacy degree from 
accredited college of pharmacy, Texas license or eligibility for Texas licensure

Fringe Benefits: UTMB is an AA/EO employer; closed major holidays and weekends; generous vacation, holiday, and sick leave; competitive benefits

Special Features: Program strengths include automated technology, telemedicine technology, ambulatory care and managed care

\section{Contact Information:}

Stephanie Zepeda

Assistant Director of Pharmacy

UTMB Correctional Managed Care

2400 Ave. I

Huntsville, TX 77340

(936) 437-5363

(936) 437-5311 (fax)

sdzepeda@utmb.edu

\section{UPMC HEALTH PLAN}

Managed Care

Accredited: No

Length of Program: 12 months

Number of Positions: 2

Affiliation:

UPMC Health System

Application Deadline: May 20

Starting Date: July 1

Estimated Stipend: $\quad \$ 32,000$

Onsite Interview: Preferred

Educational/Special Requirements: Applicants must have completed a doctor of pharmacy degree and be eligible for Pennsylvania licensure. A pharmacy practice residency is recommended but not required for consideration. Please include letter of intent, curriculum vitae, list of references (3) with contact information, and 3 letters of recommendation.

Fringe Benefits: Health, dental, eye care, life, and disability insurance is available; vacation time is allotted and professional travel and stipend is available

Special Features: UPMC Health Plan is the second largest health insurer in western Pennsylvania, covering commercial, medical assistance, and Medicare populations; it has integrated resources from Community Care Behavioral Health, University of Pittsburgh School of Pharmacy, and the UPMC Health System.

Contact Information:

Rae Ann Maxwell

Director, Pharmacy Services

UPMC Health Plan

One Chatham Center, 5th Fl.

112 Washington Pl.

Pittsburgh, PA 15219

(412) 454-5276
(412) 454-5295 (fax)

maxwellra@msx.upmc.edu

\section{VA SAN DIEGO HEALTHCARE SYSTEM}

Managed Care Pharmacy Systems

Accredited: Application submitted

Length of Program: 12 months

Number of Positions: 1

Affiliation:

University of the Pacific School of Pharmacy

Application Deadline: January 15

Starting Date: July 1

Estimated Stipend: $\quad \$ 38,000$

Onsite Interview: Yes

Educational/Special Requirements: PharmD plus first-year residency or equivalent experience, U.S. citizenship, personal statement, curriculum vitae, transcripts, and 3 letters of recommendation

Fringe Benefits: 12-13 vacation and sick leave days, 11 federal holidays, health and life insurance, free parking, paid leave, tuition and travel to required events, office with up-to-date computer systems

Special Features: This second-year residency will provide the skills necessary for the practical application of pharmacoeconomic principles to formulary management and outcomes research in integrated health care systems. Education will include formal pharmacoeconomics training classes and hands-on application of principles. Work activities will encompass the VASDHS, Veterans Integrated Service Network 22 (VISN 22) pharmacy benefits management (i.e. Southern California Regional VA), and VA national formulary tasks. Out-of-state and in-state travel is required. A university-affiliated, teaching, integrated healthcare system with 100\% computerized medical records, cutting-edge patient safety, pharmacy-managed clinics, pharmacist specialty practices, and a dedicated Pharmacy Health Outcomes Division with 4 full-time pharmacoeconomists. The pharmacy service has outstanding leadership with a long positive track record for innovation and excellence at the local, state, and national levels and a well-trained, well-published staff, most with residencies. This is an exciting opportunity to learn, and to start your career.

Contact Information:

Anthony P. Morreale, PharmD, MBA, BCPS

Chief, Pharmacy Service

VA San Diego Healthcare System

Pharmacy Service (119)

3350 La Jolla Village Dr.

San Diego, CA 92161

(858) 552-8585, ext.. 3026

(858) 552-4391 (fax) 
anthony.morreale@med.va.gov

Web: http://www.san-diego.med.va.gov

[This listing has not been not updated; contact the program for current information.]

WALGREENS HEALTH INITIATIVES

Pharmacy Benefit Manager

Accredited: AMCP/ASHP

Length of Program: 12 months

Number of Positions: 2

Affiliation:

University of Illinois, Midwestern

University-Chicago College of Pharmacy

Application Deadline: January 7

Starting Date: July 5

Estimated Stipend: $\quad \$ 36,000$

Onsite Interview: Yes

Educational/Special Requirements: PharmD

Fringe Benefits: Medical plan, 2-week vacation, holidays, travel expense budget

Special Features: This managed care pharmacy residency program is designed to allow the residents to work within the various departments of a pharmacy benefits management firm, including, but not limited to, care management, drug use policy, PBM operations, clinical sales, and specialty pharmacy. The residents will gain practical experience and develop skills related to disease management, health outcomes, medication management strategies, formulary management, drug utilization review, drug information, and other clinical services. Additionally, residents will have the opportunity to gain exposure to the pharmaceutical industry, be involved in professional organizations, and precept pharmacy students.

Contact Information:

Susie Min

Manager, Clinical Education and Shared Faculty

Walgreens Health Initiatives

1417 Lake Cook Rd., MS\# L457

Deerfield, IL 60015

(847) $964-6740$

(847) 374-2669 (fax)

susie.min@walgreens.com
WELLPOINT PHARMACY MANAGEMENT

Managed Care Pharmacy

Accredited: ASHP/AMCP

Length of Program: 12 months

Number of Positions: 1

Affiliation: Blue Cross of California, PrecisionRx, University of Southern California

Application Deadline: January 15

Starting Date: July 1

Estimated Stipend: $\quad \$ 50,000$

Onsite Interview: Yes

Educational/Special Requirements: PharmD from an ACPEaccredited college of pharmacy or equivalent experience, eligibility for California licensure, good academic standing, excellent written and verbal communication skills

Fringe Benefits: Health insurance; 2 weeks paid vacation; paid holiday and sick days; attendance at the Western States Conference, at a national pharmacy organization meeting, and at a WellPoint Pharmacy Management National P\&T meeting Special Features: The program is designed to provide the resident with an overall managed care experience. The resident rotates through several areas within the PBM, including drug information, therapy management, clinical account management, clinical product development, clinical intervention and prior authorization centers, mail-order and specialty pharmacy, health informatics and policy research, and pharmaceutical contracting and industry relations. The program also includes rotations at the Blue Cross of California health plan and the University of Southern California direct-patient-care sites.

\section{Contact Information:}

Krista Yokoyama

Residency Program Director

WellPoint Pharmacy Management

8407 Fallbrook Ave.

MS AF-7

West Hills, CA 91304

(818) 313-5082

(818) 313-5110 (fax)

krista.yokoyama@wellpoint.com 